\title{
Five Thousand Downloads
}

\author{
H L Vacher \\ Department of Geology, University of South Florida, Tampa FL, vacher@usf.edu
}

Follow this and additional works at: https://digitalcommons.usf.edu/numeracy

Part of the Mathematics Commons, and the Science and Mathematics Education Commons

\section{Recommended Citation}

Vacher, H L. "Five Thousand Downloads." Numeracy 3, Iss. 1 (2010): Article 1. DOI: http://dx.doi.org/ 10.5038/1936-4660.3.1.1 


\section{Five Thousand Downloads}

Creative Commons License

(c) (i) (8)

This work is licensed under a Creative Commons Attribution-Noncommercial 4.0 License 
Numeracy went live with volume 1, issue 1, on December 20, 2007, eagerly ahead of the January 12008 launch date. In its first two years (four issues), the journal has published 15 articles, three perspectives pieces, six book reviews, and seven editorials and columns (Table 1).

As of December 18, 2009-two years after the launch-PDFs of those 31 papers have been downloaded a total of 5,615 times: 2,419 in 2008 (including 61 in the last ten days of 2007) and 3,196 in the first 50 weeks of 2009 . We passed the 5000 full-text download milestone on October 20, 2009 (Fig. 1).

$$
* * * *
$$

Table 1.

Papers in Numeracy

\begin{tabular}{lllll} 
& \multicolumn{4}{c}{ Issue } \\
\cline { 2 - 5 } & $1(1)$ & $1(2)$ & $2(1)$ & $2(2)$ \\
\cline { 2 - 5 } Editorials & 1 & 1 & 1 & 1 \\
Articles & 4 & 4 & 4 & 3 \\
Perspectives & 1 & 1 & & 1 \\
Book reviews & 1 & 1 & 1 & 3 \\
Columns & & 1 & 1 & 1 \\
\hline
\end{tabular}

The rate of Numeracy downloads is clearly increasing. During the 12.3 months of downloads attributed to 2008 , there were 197 downloads/ month. During the 11.5 months of 2009 thus far, there have been 277 downloads/month. For the 23month period through November 2009 (see Appendix), the average was 235 downloads/month, about $10 \%$ larger than the 221-downloads/ month slope of the linear trend line $\left(R^{2}=0.990\right)$ of cumulative monthly downloads (Fig. 2). The trajectory of the cumulative downloads broke through the linear trend in mid2009.

A quadratic function gives a better fit $\left(R^{2}=0.997\right)$ (Fig. 3). The leading coefficient implies an acceleration of about 4 downloads/ month/month. If the quadratic model holds, there will be an additional 3,660 downloads between now ( $x=23.5$ months) and mid-December 2010 ( $x=35.5$ months), thus an average of ten downloads per day in

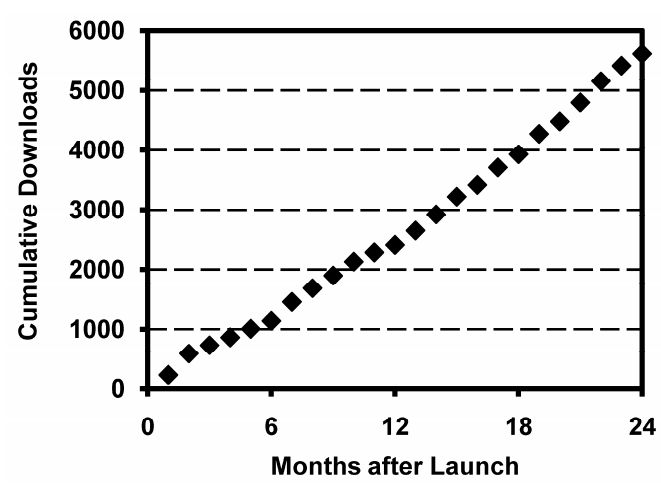

Figure 1. Cumulated monthly downloads from January 1, 2008.

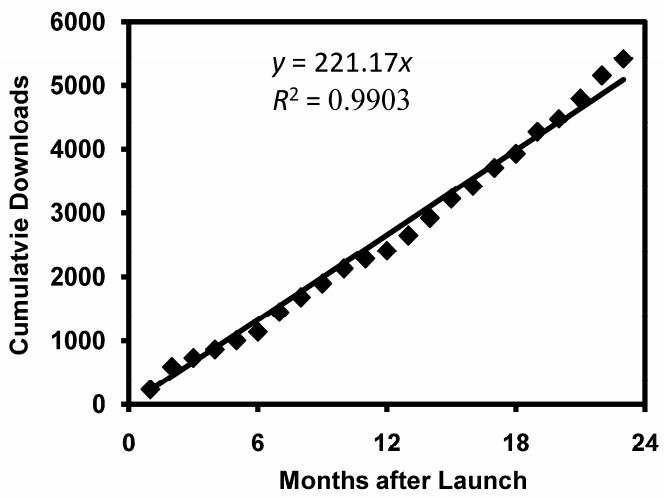

Figure 2. Linear model. 
2010. This time next year, the trajectory will have just broken through the 9000 mark, heading for 10,000 on March 2, 2011 ( $x=38.07$ months).

$* * * *$

The structure lying beneath the Numeracy download trajectory can be seen in the stacked bar graph of Figure 4. The trajectories of individual issues are convex upward. With varying success, they can be fit with power functions (Table 2). Together they aggregate to the quadratic function for the journal as a whole shown in Figure 3.

On March 2, 2011, when the total downloads are scheduled to reach 10,000 by the quadratic model, the trajectories for the individual issues will have reached 3,642 [1(1)], 2,028 [1(2)], 2,509 [2(1)], and 1,786 [2(2)] according to extrapolation of the power functions of Table 2. Those numbers sum to 9965 , exquisitely close to 10,000 .

But summing the four power functions to produce cumulative downloads in March a year from now ignores the issues of Numeracy published between now and then. Taking a rather generic power function, $y=200 x^{0.7}$, for each of the next three issues produces 1,273 [3(1)], 865 [3(2)], and 333 [4(1)] for an additional 2,469 cumulative downloads on March 2, 2011. This augmented trajectory crosses the 10,000 mark on October 3, 2010 - this year!

On the other hand, applying the generic power function across the board to all the issues of Numeracy past and future produces a trajectory for the sum that 
predicts 4,938 downloads at the end of November, 2009 (vs. actual 5,415) and breaks 10,000 on January 9, 2011.

$$
* * * *
$$

I have bolded the dates from the projections so that I can find them easily next year at this time-not because I believe any of them particularly. After all, one of the concepts that the real world brings to quantitative literacy is a governor on extrapolation: "Prediction is hard-especially about the future" (variously attributed to Yogi Berra and Niels Bohr; repeated often by economists, groundwater modelers, and many others). But Yogi Berra also said (actually it's the title of one of his books), "You can observe a lot by watching." We have watched as downloads reached 5,000 in just 22 months. We have watched as a month's downloads have increased from one year to the next (Appendix). And so now we look forward to watching as downloads reach 10,000 - probably sooner than the journal's $44^{\text {th }}$ month; possibly in months 34 to 39 . Three years ago (December 2006), when the editors and some of the associate editors and NNN officers met at Dartmouth to plan the journal, we didn't know what to expect.

\section{Appendix. Monthly Downloads 12/2007 - 11/2009}

\begin{tabular}{lrrrrr} 
& \multicolumn{3}{c}{ Issue } & Total \\
\cline { 2 - 4 } Month & $1(1)$ & $1(2)$ & $2(1)$ & $2(2)$ & \\
\hline Dec-07 & 61 & & & & 61 \\
Jan-08 & 169 & & & & 169 \\
Feb-08 & 358 & & & & 358 \\
Mar-08 & 141 & & & & 141 \\
Apr-08 & 133 & & & & 133 \\
May-08 & 144 & & & & 144 \\
Jun-08 & 132 & & & & 132 \\
\hline Jul-08 & 124 & 190 & & & 314 \\
Aug-08 & 126 & 106 & & & 232 \\
Sep-08 & 119 & 94 & & & 213 \\
Oct-08 & 109 & 124 & & & 233 \\
Nov-08 & 49 & 105 & & & 154 \\
Dec-08 & 50 & 75 & 10 & & 135 \\
\hline Jan-09 & 58 & 72 & 100 & & 230 \\
Feb-09 & 69 & 62 & 141 & & 272 \\
Mar-09 & 96 & 74 & 128 & & 298 \\
Apr-09 & 55 & 32 & 110 & & 197 \\
May-09 & 81 & 76 & 134 & & 291 \\
Jun-09 & 60 & 61 & 100 & 7 & 228 \\
\hline Jul-09 & 52 & 56 & 67 & 162 & 337 \\
Aug-09 & 31 & 46 & 52 & 79 & 208 \\
Sep-09 & 73 & 73 & 54 & 116 & 316 \\
Oct-09 & 93 & 59 & 76 & 129 & 357 \\
Nov-09 & 63 & 39 & 37 & 123 & 262 \\
\hline Total & 2446 & 1344 & 1009 & 616 & 5415 \\
\hline & & & & &
\end{tabular}

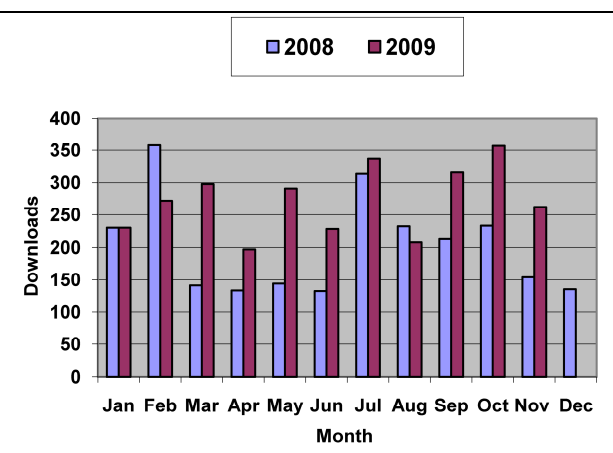

Figure A1. Observations.

There was an initial spurt of downloads associated with the kickoff of the journal.

There is a periodicity reflecting the schedule of January and July issues that was evident in the first year, less so in the second.

Generally for a given month, there has been an increase of downloads from the first year to the second. 